\title{
İyimserlik, Özgecilik ve Medeni Durumun Psikolojik Dayanıkılık Üzerindeki Etkileri
}

\author{
The Effects of Optimism, Altruism and Marital Status on the \\ Psychological Resilience \\ İzzet PARMAKSIZ1
}

• Geliş Tarihi: 11.06.2019 • Kabul Tarihi: 17.07.2019• Çevrimiçi Yayın Tarihi: 17.07.2019

\begin{abstract}
$\ddot{\mathbf{O z}}$
Bu çalışmada iyimserlik ve özgeciliğin psikolojik dayanıklılığı yordamadaki gücünü saptamak amaçlanmıştır. Örneklem Orta Anadolu'da yaşayan 389 (Kadın:198, Erkek:191) yetişkin katılımcıdan oluşmaktadır. Bu araştırmada İyimserlik Ölçeği, Özgecilik Ölçeği, Psikolojik Dayanıklılık Ölçeği ve araştırmacı tarafından geliştirilen kişisel bilgi formu kullanılmıştır. Veri analizinde hiyerarşik regresyon analizi, t-testi ve ANOVA ve pearson korelasyonu kullanılmıştır. Medeni durum dummy değişken olarak regresyon analizine dahil edilmiştir. Regresyon analizine dahil edilen nicel değişkenler arasında pozitif yönlü anlamlı bir ilişki saptanmıştır. Yapılan analizlerde medeni durumun psikolojik dayanıklılık puanlarını anlamlı farklılaştırdığı saptanmıştır. Buna karşın cinsiyet, yaşanan yer, eğitim düzeyi ve ekonomik durum psikolojik dayanıklılık puanları üzerinde anlamlı bir farklılık oluşturmamıştır. Yapılan regresyon analizinde katılımcıların iyimserliklerinin, özgeci davranışlarının ve medeni durumlarının psikolojik dayanıklılığı yordadığı saptanmıştır. Koruyucu ve önleyici ruh sağlığı hizmeti veren bireylerin yapacakları teorik ve uygulamalı eğitimlere iyimserlik, özgecilik kavramlarını tanıtıcı ve kazandırıcı etkinlikler eklemelerinin faydalı sonuçlar vereceği düşünülmektedir. Ayrıca bireyi ruh sağlığı anlamında güçlendiren ve yalnızlıktan uzaklaştırmak için birinci derece öneme sahip sosyal destek mekanizmalarının önemi konusunda bireyleri bilinçlendirmek için faaliyetler yürütülebilir.
\end{abstract}

Anahtar sözcükler: psikolojik dayanıklılık, iyimserlik, özgecilik, medeni durum

\section{Atıf:}

Parmaksız, İ. (2020). İyimserlik, özgecilik ve medeni durumun psikolojik dayanıklılık üzerindeki etkileri. Pamukkale Üniversitesi Ĕ̈itim Fakültesi Dergisi, 48, 285-302. doi 10.9779/pauefd.576186

\footnotetext{
* Dr. Öğr. Üyesi, Niğde Ömer Halisdemir Üni. Eğitim F. Eğitim Bil. Böl. Psikolojik Danışma ve Rehberlik ABD., izparm44@gmail.com, https://orcid.org/0000-0003-2468-6134
} 


\begin{abstract}
The aim of this study was to determine the strength of optimism and altruism in predicting psychological resilience. The sample consists of 389 (Female: 198, Male: 191) adult participants living in Central Anatolia. In this study, Optimism Scale, Altruism Scale, Psychological Resilience Scale and personal information form developed by the researcher were used. Hierarchical regression analysis, $t$ test and ANOVA and Pearson correlation were used to analyze the data. Marital status was included as a dummy variable in regression analysis. A positive significant relationship was found between the quantitative variables included in the regression analysis. In the analyzes, it was found that marital status significantly differentiated psychological resilience scores. On the other hand, gender, place of living, education level and economic status did not differ significantly. In the regression analysis, it was found that the optimism, altruistic behavior and marital status of the participants predicted their psychological resilience. It is thought that adding optimistic and altruistic activities to the theoretical and practical trainings of protective and preventive mental health service individuals will give beneficial results. Social support strengthens the individual in terms of mental health and removes it from loneliness. Activities can be carried out to raise awareness of individuals.
\end{abstract}

Keywords: psychological resilience, optimism, altruism, marital status

\title{
Cited:
}

Parmaksiz, İ.(2020). The effects of optimism, altruism, and marital status on the psychological resilience.

Pamukkale Üniversitesi Eğitim Fakültesi Dergisi, 48, 285-302. doi: 10.9779/pauefd.576186 


\section{Giriş}

Günümüz toplumunu düşündüğümüzde artık problemler kaçınılmaz hale gelmiştir. İnsanların giderek daha fazla hassaslaşması ruh sağlığını etkileyen dinamiklerin daha dikkatlice ele alınmasını gerektirmektedir. $\mathrm{Bu}$ nedenle toplumu oluşturan yapıyı dinamik tutmak için stresörleri kontrol altına almak çok önemlidir. Ruh sağlığı alanındaki çalışmacıların bir yönden de amacı; bireyin yaşam kalitesini ve mutluluğunu dolaylı olarak da yaşam doyumunu artırmaktır (Seligman, 1998). Bunu sağlamanın da bireylerin dayanıklılığını artırmakla olabileceği düşünülmektedir. Bu açıdan psikolojik dayanıklılı̆̆ etkileyen faktörlerin dikkatle ele alınması gerekmektedir. İyimser tutum (Şahin, 2015), özgeci davranış (Tümlü ve Recepoğlu, 2013) ve medeni durum (Bozgeyikli ve Şat, 2014) değişkenlerinin farklı örneklem gruplarında psikolojik dayanıklılıkla ilişkili olduğu saptanmıştır. Bu çalışmada ise bu değişkenlerin psikolojik dayanıklılık üzerindeki yordayıcı etkisi ele alınmıştır.

\section{Psikolojik Dayanıklılık}

Problem kaçınılmaz ise problemli durumlardan güçlenmiş olarak çıkmak önemlidir. Bu açıdan gelişmek için üzerinde durulan kavramlardan biri de, negatifliğe ya da dezavantajlara odaklanmak yerine, bireyin güçlü yönlerini ön plana çıkaran psikolojik dayanıklılıktır (Wang ve Zhang, 2015). Psikolojik dayanıklılık, stresli zamanlarda kişinin performansı, sağlığı ve ruhsal durumunun iyi olmasını ifade eden bir kişilik özelliğidir (Maddi, 1998). Herrman vd., (2011) psikolojik dayanıklılığın çoğunlukla pozitif uyum, zorlu yaşam olayları sonrasında ruh sağlığının korunması ya da tekrardan kazanılması anlamında kullanıldığını belirtmişlerdir. Psikolojik dayanıklılığı yüksek olan kişiler hayata dair olumlu duygulara sahip kişilerdir (Atarbay, 2017). Ayrıca insanların sosyal destek mekanizmaları güçlü olduğunda psikolojik dayanıklılıkları da artmaktadır. (Kobau vd., 2011). Psikolojik dayanıklılık çözüm odaklı baş etme ve problemi kontrol altında tutmaya yönelik tutumları içermektedir (Folkman ve Lazarus, 1990). Bu durumda psikolojik dayanıklılık, stresin negatif sonuçlarını azaltan ve uyum sağlamayı kolaylaştıran bir nitelik olarak kendini göstermektedir (Jacelon 1997). Aynı zamanda psikolojik dayanıklılık öğrenilebilir bir özelliktir (Beardslee ve Podorefsky 1998). Bu nedenle psikolojik dayanıklılı̆̆ sağlayabilmek için bu özelliği güçlendiren iyimserlik ve özgeci davranışı da bilmek önemlidir.

\section{İyimserlik}

İyimserlik, yaşamın bütün alanlarına genellenen ve değişmez bir biçimde sürdürülen olumlu bakış açısı olarak (Abraham, 2007) bireyin geleceğine dair olumlu inançlarıdır (Gillham ve Reivich, 2004). İyimserlik en kötü koşullarda bile olumlu bakış açısı ve olumlu beklentiler geliştirmeyi sağlar. Burada söz konusu olan her koşulda olumlu bakış açısı geliştirebilmenin temelinde, sosyal destek kaynaklarına ulaşabilmek kadar şans faktörlerine ya da koruyucu bir güce sığınmanın rolü de bulunmaktadır (Magno, Parinas, ve Mamauag, 2008). Kişilik gelişimi açısından bakıldığında koruyucu bir faktör olarak karşımıza çıkmaktadır (Karaırmak, 2007; Benson, 2007). Ayrıca iyimserlik, psikolojik iyilik halini arttırmada özellikle faydalı olabilir (Carver ve Scheier, 2014) ve bireyin hedefleri davranışa dönüştürme kapasitesine katkıda bulunarak (Boehm, Chen, Williams, Ryff, Kubzansky, 2015) bireyin kendini iyi hissetmesini sağlayabilir. Ayrıca insanın eyleme geçmesinde sahip olduğu iyimser tutumun rolü çok 
önemlidir (Balc1 ve Y1lmaz, 2002). Çünkü iyimser bireyler olumsuz olaylardan, umutsuzluktan ve suçluluk duygusundan kendilerini uzak tutarlar (Kesken ve Ayyıldız, 2008). Araştırmalarda, iyimser insanların daha iyi fiziksel ve zihinsel sağlığa, daha uzun ömre, daha olumlu sosyal ilişkilere ve daha iyi başa çıkma becerilerine sahip oldukları ifade edilmektedir (Castro-Schilo vd., 2013; Taylor vd., 2012). Bu durum da daha iyi bir ruh sağlığı olarak kendini göstermektedir.

\section{Özgecilik}

Özgecilik başkalarına yardım etmenin sağladığı memnuniyet duygusu dışında karşılık beklemeden gönüllü olarak iyilik yapmaktır (Taylor, Peplau ve Sears, 2010). Özgecilik bir anlamda başkalarının sorunlarına karşı hissedilen empati duygusunun davranışsal yönüdür (Eisenberg, Fabes ve Spinrad, 2006). Bu açıdan pek çok sosyal davranışı da içinde barındırmaktadır (Batson, 2003). Budak (2009)'a göre özgeci davranışta esas olan başkasının yararına hareket etme ve kendi çıkarından çok başkasının yararını düşünmektir. Özgecilik beklentisiz iş yapmaktır. Bu çıkarsız davranış kişinin kendini iyi hissetmesini sağlar. Çünkü mutlu olmanın yollarından biri de insanlara karşlık beklemeden yardım etmektir (Seligman, 2007). Sağlıklı olmayı kendini gerçekleştirme olarak tanımlayan Maslow’a (2001) göre özgecilik, bireyin kendini gerçekleştirme düşüncesiyle birlikte ruh sağlığının da aracı değişkenidir. Özgeci davranış öğrenme sonucu ve model alınarak elde edilebileceğinden (Lee, Piliavin ve Call, 1999) bu davranışın bireylere kazandırılmasıyla insanların ruh sağlığına olumlu etkide bulunulabilir.

\section{Psikolojik Dayanıklılık, Özgecilik ve İyimserlik Arasındaki İlişkiler}

Yaşadığımız çağ ruh sağlığını tehdit edici pek çok riski barındırmaktadır. Bu açıdan insanlara, ruh sağlı̆̆ını koruyucu olumlu özellikleri kazandırmak çok önemlidir. Çünkü bireylerin ruh sağlığını tehdit eden risklere karşı dayanıklılığı artıran özelliklerin kazandırılması onları bu risklerden korumaktadır. Olumlu kişilik özelliklerden olan psikolojik dayanıklılık, iyimserlik ve özgecilik ruh sağlığını etkileyen önemli dinamiklerdir. Özgecilik iyimser olma ile ilişkili olduğu düşünülen bir kavramdır. Şahin (2015) de özgecilik ve iyimserlik arasında pozitif bir ilişki bulmuştur. Ayrıca Sezer ve Genç (2018) de iyimserlikle aynı anlamı ifade eden pozitif algı ile özgecilik arasında pozitif yönde anlamlı bir ilişki olduğunu saptamıştır.

Schwartz, Keyl, Marcum ve Bode, (2009), Weinstein ve Ryan, (2010) ve Ery1lmaz ve Ercan, (2011) özgeciliğin psikolojik iyi olmayla olumlu ilişkisinin olduğunu saptamışlardır. Cheak, (2013), Foureur, Besley, Burton, Yu ve Crisp (2013), Çam ve Büyükbayram (2015) özgeciliğin psikolojik dayanıklılığı etkileyen kişisel koruyucu faktör olduğunu saptamışlardır.

Psikolojik dayanıklılığı destekleyen en önemli kavramlardan biri de iyimser olmaktır. İyimserlik de önemli ve olumlu bir kişilik özelliğidir. Kişilik yapılanmasının da, bu kavramla ilişkili olduğu belirtilmiştir (Agaibi ve Wilson, 2005). İyimserlik gibi olumlu sonuçların doğmasına destek olan koruyucu faktörler psikolojik dayanıklılığın oluşması ve ortaya çıkmasında payı olan faktörlerdir (Aydın, 2018). Ayrıca yapılan araştırmalar psikolojik dayanıklılığ1 yordayan en önemli faktörün iyimserlik olduğunu ve aralarında güçlü bir ilişki olduğunu ortaya koymaktadır (Kumpfer, 1999; Luthar, 1999; Terzi, 2008). İyimserlik öğrenilebilir ve geliştirilebilir bir duygudur (Parmaksız ve Avşaroğlu, 2012). Teorik olarak, erken ve orta yetişkinlik döneminde ortalama iyimserlik seviyelerinin artması beklenir (Arnett, 
2006). Bu durumun sonucu olarak yetişkinlikte, iyimserlik, daha yüksek seviyelerde öznel iyi oluş sağlar (Mens, Scheier, Carver, 2016). Bunun yanı sıra insanlar iyimser bakış açılarını üzerinde etkin oldukları insanlara da öğretmektedir. Örneğin iyimserliği yüksek olan biriyle evli olan kişilerin zaman içinde daha iyimser olma eğiliminde oldukları tespit edilmiştir (Chopik, Kim ve Smith, 2015). Ayrıca yetişkinlik dönemindeki iyimserlik düzeyindeki artış, yaşamdan doyum sağlamayla dolayısıyla psikolojik olarak dayanıklı olmayla ilişkilidir (Baird, Lucas ve Donnellan, 2010; Orth ve Robins, 2014). Sonuç olarak sosyal bir varlık olan insan diğer bireylerle ilişkilerinde iyimser tutum gösterdiğinde bencil davranma eğilimini kısıtlar. Kültürel unsurların da etkili olduğu özgeci bir eğilim sergiler. $\mathrm{Bu}$ davranış eğilimi de psikolojik dayanıklılık düzeyini artırarak bireylerin ruh sağlığını olumlu etkiler.

\section{Araştırmanın Amacı}

Karacaoğlu ve Köktaş (2016) iyimserliğin psikolojik dayanıklılık üzerinde kısmi aracı rolü olduğunu; Seligman (1999) iyimserliğin esnek düşünceyi sağlayarak bireyi güçlendirdiğini ifade etmektedir. Karaırmak (2007) ise iyimserliğin dolaylı ve doğrudan psikolojik dayanıklılıkla ilişkili olduğunu bulmuştur. Bozgeyikli ve Şat, (2014) özgeci davranışın psikolojik dayanıkl1lıkla güçlü bir ilişkisi olduğunu ortaya koymuştur. Mellor vd., (2009) birine gönüllü yardım etmenin (özgeci davranış) psikolojik iyilik halini olumlu etkilediğini bulmuştur. Araştırma sonuçlarına bakılarak yetişkin bireylerin iyimser ve özgeci tutumlarının psikolojik dayanıklılığı artıracağı düşünülmektedir. Bu nedenle bu araştırmada iyimserlik ve özgeciliğin psikolojik dayanıklılığı yordayıcı etkisini saptamak amaçlanmıştır. Yetişkinlik dönemi psikolojik dayanıklılık çalışmalarının sayıca az olduğu bilinmektedir (Bonanno, 2004). Alan yazına özellikle örneklem grubu olarak özgün bir katk1 sağlayacağı düşünüldüğünden bu çalışma önem arz etmektedir.

\section{Yöntem}

$\mathrm{Bu}$ araştırma, yetişkin bireylerde iyimserlik ve özgeciliğin psikolojik dayanıklılıkla ilişkisini incelemeye yönelik ilişkisel bir çalışmadır. $\mathrm{Bu}$ araştırmada tarama modeli kullanılmıştır. Tarama modelinde amaç bir durumu betimlemek ya da keşfetmektir (Babbie, 2012). Tarama modeli ile elde edilen veriler ise t-testi, Anova ve hiyerarşik regreyon analizi yöntemiyle analiz edilmiştir.

$\mathrm{Bu}$ araştırmada aşağıdaki araştırma sorularına cevap aranmıştır.

1. Demografik değişkenlerin psikolojik dayanıklılıkla ilişkisi nedir?

2. İyimserlik, özgecilik ve medeni durum psikolojik dayanıklılığı yordamakta mıdır?

Veri analizinde kullanılan hiyerarşik regresyon analizi aşağıdaki modele göre yapılmıştır.

Model 1: Psikolojik Dayanıklılık = Sabit + Medeni Durum (Dummy Değişken)

Model 2: Psikolojik Dayanıklılık = Sabit + Medeni Durum (Dummy Değişken) + İyimserlik

Model 3: Psikolojik Dayanıklılık = Sabit + Medeni Durum $($ Dummy Değişken $)+$ İyimserlik + Özgecilik 


\section{Çalışma Grubu}

Araştırma grubu 2019 yılında Orta Anadolu'da yaşayan yetişkin bireylerden oluşmaktadır. Çalışmaya dahil olan bireyler rastgele belirlenmiş gönüllü katılımcılardır. Katılımcılar 191'i (\%49.1) erkek 198'i (\%50.9) kadın olmak üzere toplam 389 kişidir. Yaşları 20-73 arasında değişmektedir $(\mathrm{M} \pm \mathrm{SD}=30.17 \pm 10.65)$.

Tablo 1. Katılımcıların Sosyo-Demografik Özellikleri

$\begin{array}{llllll}\text { Cinsiyet } & N & \text { Medeni Durum } & \text { Yaş } \quad \text { Eğitim Düzeyi } & \text { Yaşadığı Yer } & \begin{array}{c}\text { Ekonomik } \\ \text { Durum }\end{array}\end{array}$

\begin{tabular}{|c|c|c|c|c|c|c|c|c|c|c|c|c|c|c|c|c|}
\hline & & $\overrightarrow{\bar{\lambda}}$ & 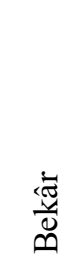 & $\bar{x}$ & 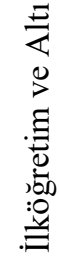 & 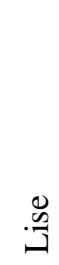 & 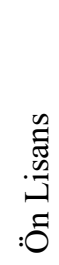 & 营 & 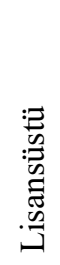 & : & 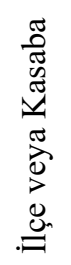 & $=$ & 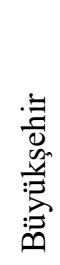 & 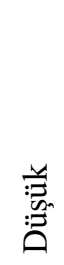 & 苟 & 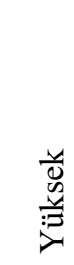 \\
\hline Kadın (f) & 198 & 80 & 118 & 29.39 & 26 & 24 & 23 & 118 & 7 & 30 & 49 & 93 & 26 & 12 & 170 & 16 \\
\hline Erkek (f) & 191 & 79 & 112 & 30.97 & 8 & 25 & 24 & 122 & 12 & 31 & 36 & 85 & 39 & 10 & 154 & 27 \\
\hline
\end{tabular}

\section{Veri Toplama Araçları:}

\section{Iyimserlik ölçeği}

Bu ölçek iyimserlik düzeyini ölçmek amacıyla Balcı ve Yılmaz'ın (2002) geliştirdiği 24 maddeden oluşan 4'lü likert tipi bir ölçme aracıdır. Ölçeğin iç tutarlılığını saptamak için hesaplanan Cronbach's $\alpha$ iç tutarlılık katsayısı .96'dır. Pearson Momentler korelasyon katsayısı .61 'dir. Testi yarılama yöntemiyle hesaplanan güvenirlik katsayısı ise .91'dir. Geçerlik için hesaplanan korelasyon katsayısı 55'tir. Ölçeğin maddelerinin yapı geçerliliğine ve alt boyutlarının olup olmadığına bakmak için faktör analizi tekniği kullanılmıştır. 24 maddeden biri hariç (1. madde) birinci faktörde toplandığı saptanmıştır. Ölçekten alınabilinecek puan 24 ile 96 aralığındadır. Yüksek puan bireyin "iyimser" olduğunu göstermektedir. 1, 6, 8, 9, 11 numaralı maddeler için ters kodlama yapılmaktadır. Bu araştırma için hesaplanan güvenirlik katsayısı .86 'dir.

\section{Özgecilik ölçeği}

Doğan ve Sapmaz (2015) tarafindan geliştirilmiştir. Ölçek 15 maddeden oluşmakta ve tek boyutludur. Ölçek 5'li likert tip puanlama sistemine sahiptir. Ölçeğin Cronbach's $\alpha$ iç tutarlılık katsayıs1 .84; test tekrar test güvenirlik katsayısı ise .74'tür. Ölçekten alınan yüksek puan, özgecilik düzeylerinin yüksek olduğunu göstermektedir. Ölçekte 2. 3. 7. 8. ve 10. maddeler ters puanlanmaktadır. Bu araştırma için hesaplanan güvenirlik katsayısı .83 'tür.

\section{Psikolojik dayanıklılık ölçeği}

Friborg vd.,' nin 2005 y1lında geliştirdiği ölçek, Basım ve Çetin (2011) tarafından Türkçe’ye uyarlanarak geçerlik ve güvenirliliği yapılmıştır. 5'li likert tipi bir ölçektir. Ölçek 33 maddeden oluşmaktadır. Puanlar arttıkça psikolojik dayanıklılık da artar. Ölçekteki; 1,3,4, 8, 11, 12, 13, 
$14,15,16,23,24,25,27,31,33$ numaralı maddeler tersten puanlanır. Ölçeğin toplam Cronbach's $\alpha$ katsayısı ise 0.90 olarak hesaplanmıştır. Bu araştırma verileriyle hesaplanan faktör analizinde promax tekniği kullanılmış ve analiz sonucunda toplam varyansın \% 47'sini açıklayan ve öz değeri 1'den büyük olan 6 faktör elde edilmiştir. Bu sonuçlar ölçeğin yap1 geçerliğine sahip olduğunu göstermektedir. Bu araştırma için hesaplanan güvenirlik katsayısı $.88^{\prime}$ dir.

\section{Kişisel bilgi formu}

Araştırmadaki bağımsız değişkenlerden olan yaş, cinsiyet, medeni durum, eğitim düzeyi, yaşanan yer ve algılanan ekonomik durum gibi değişkenlerin kullanıldığı araştırmacı tarafından geliştirilmiş bir formdur.

\section{İşlem}

Araştırmanın yapılabilmesi için seçilen gönüllü katılımcılara iyimserlik ölçeği, özgecilik ölçeği, psikolojik dayanıklılık ölçeği ve kişisel bilgiler formu araştırmacı tarafindan uygulanmıştır. Katılıcılara uygulama öncesinde araştırmanın amacı anlatılarak ölçekleri rahatça cevaplandırabilecekleri bir ortam ve zaman sağlanmıştır. Araştırmacı ölçekle ilgili yönergeyi verdikten sonra araştırmacının gözetiminde ölçekler cevaplandırılmıştır. Uygulamalar yaklaşık 25 dakika sürmüştür.

\section{Verilerin Analizi}

$\mathrm{Bu}$ araştırmada bağımlı değişken ile bağımsız değişken arasındaki ilişkiye bakılmış ve ilk adım olarak da varyansların homojenliği (normal dağılım) incelenmiştir. Levene testi sonuçları tüm değişkenler için $p>0.05$ dır. Sonucun anlamlı olmaması dağılımın normal olduğunu ifade etmektedir. Çarpıklık değeri tüm değişkenler için - 0.55 ile -0.14 aralığındadır; basıklık değerinin ise tüm değişkenler için - 0.70 ile 0.37 aralığında olduğu hesaplanmıştır. Çarpıklık ve basıklık katsayılarının \pm 1 sınırlarında olması, puanların normalden aşırı sapma göstermediğini ifade eder (Büyüköztürk, Çokluk ve Köklü, 2010). Skewness değerlerinin +1 ve -1 arasında kurtosis değerlerinin de +2 ile -1 arasında olmasının da normal olduğu belirtilmektedir (Huck, 2008). Bu istatistiksel analiz sonuçlarına göre örneklem grubumuz normal dağılıma sahiptir. Veriler üzerinde ikili karşılaştırmalarda t-testi, çoklu karşılaştırmalarda tek yönlü varyans analizi (ANOVA) kullanılmıştır. Yordayıcı etkiyi saptamak için ise hiyerarşik regresyon analizi tekniği kullanılmıştır. Verilerin aykırı değere sahip olup olmadığına bakmak için Mahalanobis uzaklık değerine sahip olan aykırı değerlerin hesaplaması yapılarak aykırı değere sahip 11 veri, veri setinden çıkarılmıştır. Bağımsız değişkenler arasındaki ikili korelasyonlar orta düzeydedir. $\mathrm{Bu}$ bulgu değişkenler arasında çoklu bağlantının olmadığını anlamına gelir. Tolerans ve VIF değerleri kabul edilir sınırlar içindedir. Otokorelasyonu test etmede kullanılan Durbin-Watson değeri 1.93 'tür. Veriler SPSS 22 programında çözümlenmiştir.

\section{Bulgular}

Psikolojik dayanıklılık çeşitli değişkenlere göre incelenmiştir. Bu amaçla elde edilen bulgular aşağıda verilmiştir.

Katılımcıların psikolojik dayanıkl1lık toplam puanının cinsiyet $\left(\mathrm{t}_{(2-387)}=-1.60, \mathrm{p}>0.05\right)$ değişkenine göre ortalamalar arası farkın anlamlı olmadığı bulunmuştur. Medeni durum $\left(\mathrm{t}_{(2-387)}=\right.$ 
3.87, $\mathrm{p}<0.001$ ) değişkenine göre ise ortalamalar arası farkın anlamlı olduğu bulunmuştur. (Tablo 2) Bu bulguya göre, evli bireylerin psikolojik dayanıklılık düzeyleri daha yüksektir.

Tablo 2. Psikolojik Dayanıklıığın Çeşitli Değişkenlere Göre t-Testi Sonuçları

\begin{tabular}{lllcccc}
\hline \multicolumn{1}{c}{ Değişkenler } & & $\mathbf{N}$ & $\overline{\mathbf{X}}$ & $\mathbf{s S}$ & $\mathbf{t}$ & $\mathbf{p}$ \\
\hline \multirow{2}{*}{ Cinsiyet } & Erkek & 191 & 125.53 & 19.27 & \multirow{2}{*}{0.11} \\
& Kadın & 198 & 128.55 & 17.96 & & 0.1 \\
\multirow{2}{*}{ Medeni Durum } & Evli & 159 & 131.39 & 18.82 & \multirow{2}{*}{0.87} & 0.00 \\
& Bekar & 230 & 124.08 & 17.97 & & \\
\hline
\end{tabular}

Katılımcıların psikolojik dayanıkl1lık toplam puanının ekonomik durum alg1s1 $\mathrm{F}_{(3-386)}=$ $2.58, \mathrm{p}>0.05)$, yaşadığ1 yer $\left.\mathrm{F}_{(4-385)}=2.25, \mathrm{p}>0.05\right)$ ve eğitim düzeyi $\left.(5-384)=0.70, \mathrm{p}>0.05\right)$ değişkenlerine göre puanlar arası farkın anlamlı olmadığı bulunmuştur. (Tablo 3).

Tablo 3. Psikolojik Dayanıklıı̆̆ın Tek Yönlü Varyans Analizi (ANOVA) Sonuçları

\begin{tabular}{llccccc}
\hline \multicolumn{1}{c}{ Değişkenler } & & $\mathbf{N}$ & $\overline{\mathbf{X}}$ & ss & $\mathbf{F}$ & $\mathbf{p}$ \\
\hline \multirow{5}{*}{ Eğitim Düzeyi } & İlköğretim ve Altı & 34 & 127.14 & 16.08 & & \\
& Lise & 49 & 124.69 & 20.45 & & \\
& Ön Lisans & 47 & 126.72 & 19.19 & 0.54 & 0.70 \\
& Lisans & 240 & 127.22 & 18.83 & & \\
& Yüksek Lisans & 19 & 132.00 & 14.65 & & \\
Kaşadığı Yer & Köy & 61 & 127.95 & 18.63 & & \\
& Kasaba ve İlçe & 85 & 123.57 & 17.64 & \multirow{2}{*}{2.25} & \multirow{2}{*}{0.08} \\
& İl & 178 & 129.29 & 18.75 & & \\
& Büyükş̧ehir & 65 & 124.70 & 19.13 & & \\
Ekonomik Durum Algısı & Oüşük & 22 & 118.95 & 21.22 & & \\
& Yüksek & 324 & 127.25 & 18.02 & 2.58 & 0.08 \\
& Orta & 43 & 129.81 & 21.19 & & \\
\hline
\end{tabular}

Katılımcıların iyimserlikleri, özgeci davranışları ve psikolojik dayanıklılık düzeyleri arasındaki korelasyon katsayıları aşağıdadır. Tablo 4 incelendiğinde, iyimserlik puanları ve özgecilik puanları arasında ( $\mathrm{r}=0.49)$, iyimserlik puanları ve psikolojik dayanıklılık puanları arasında $(\mathrm{r}=0.51)$, özgecilik puanları ve psikolojik dayanıklılık puanları arasında $(\mathrm{r}=0.39)$ pozitif yönlü güçlü bir ilişki olduğu; medeni durum ve psikolojik dayanıklılık puanları arasında ( $\mathrm{r}=$ -0.19) negatif yönlü güçlü bir ilişki olduğu saptanmıştır. 
Tablo 4. Değişkenler Arasındaki Korelasyon Katsayıları

\begin{tabular}{ccccc}
\hline Değişkenler & MD & I & Ö & PD \\
\hline MD & 1.00 & & & \\
$\dot{I}$ & $-0.20^{*}$ & 1.00 & & \\
$\ddot{O}$ & 0.02 & $0.49^{*}$ & 1.00 & 1.00 \\
PD & $-0.19^{*}$ & $0.51^{*}$ & $0.39 *$ & \\
\hline
\end{tabular}

$* \mathrm{p}<.01$

İ: Lyimserlik, Ö: Özgecilik, PD: Psikolojik Dayanıklılık, MD: Medeni Durum

\section{Regresyon Analizi Sonuçları}

Katılımcıların iyimserlik ve özgecilik puanlarının psikolojik dayanıklılık puanlarını yordayıp yordamadığı hiyerarşik regresyon analizi ile incelenmiş̧ir. "Medeni durum" değişkenine göre psikolojik dayanıklılık puanları farklılık gösterdiği için bu değişken "dummy değişken" olarak tanımlandıktan sonra hiyerarşik regresyon analizine dahil edilmiştir. Analiz sonuçları Tablo 5 'tedir.

Tablo 5. Medeni Durum, İyimserlik ve Özgecilik Puanlarının Psikolojik Dayanıklılığı Yordamasına İlişkin Hiyerarşik Regresyon Analizi Sonuçları

\begin{tabular}{|c|c|c|c|c|c|}
\hline Bağımlı Değişken & Bağımsız Değişken & $\mathbf{R}^{2}$ & $\mathbf{F}$ & $\beta$ & $\mathbf{t}$ \\
\hline \multirow{3}{*}{ Psikolojik Dayanıklılık } & $\begin{array}{l}\text { 1. Adım } \\
\text { Medeni Durum }\end{array}$ & 0.04 & $14.94 *$ & -0.19 & $-3.86^{*}$ \\
\hline & $\begin{array}{l}\text { 2. Adım } \\
\text { Medeni Durum } \\
\text { Iyyimserlik }\end{array}$ & 0.27 & $71.19 *$ & $\begin{array}{r}-0.09 \\
0.49\end{array}$ & $\begin{array}{l}-2.17^{* *} \\
11.07^{*}\end{array}$ \\
\hline & $\begin{array}{l}\text { 3. Adım } \\
\text { Medeni Durum } \\
\text { İyimserlik } \\
\text { Özgecilik }\end{array}$ & 0.30 & $54.67 *$ & $\begin{array}{l}-0.11 \\
0.39 \\
0.19\end{array}$ & $\begin{array}{c}-2.56^{* *} \\
7.78^{*} \\
4.00^{*}\end{array}$ \\
\hline
\end{tabular}

$* \mathrm{p}<0.001 * * \mathrm{p}<0.05$

İyimserlik psikolojik dayanıklılığı medeni durum kontrol değişkeniyle birlikte \%27 yordamaktadır. Bu iki değişkene özgeci davranışın da eklenmesiyle yapılan analizde \%30 gibi yüksek düzeyde yordayıcılık saptanmıştır.

\section{Tartışma}

$\mathrm{Bu}$ çalışmada özgeci tutum, iyimser tutum ve medeni durumun yetişkinlerin psikolojik dayanıklılıkları üzerindeki etkisini saptamak amaçlanmıştır. Bulgular, yetişkin bireylerin iyimser ve özgeci tutumlarındaki artışın psikolojik dayanıklılık düzeyinin artmasına katkı sağladığını ortaya koymaktadır. Bu veriler iyimserlik, özgecilik ve medeni durumun psikolojik dayanıklılığı yordadığını göstermektedir.

Araştırma bulgularına göre cinsiyet, yaşanan yer, ekonomik durum ve eğitim düzeyi psikolojik dayanıklılık puanlarını anlamlı düzeyde farklılaştırmamaktadır buna karşın medeni durum psikolojik dayanıklılık puanlarını anlamlı düzeyde farklılaştırmaktadır. 
Araştırma bulgularına göre yaşanan yer psikolojik dayanıklılık puanlarını anlamlı farklılaştırmamaktır. Bu durum psikolojik dayanıklılığın yaşanan yerle ilgili olmadığını diğer değişkenlerin ruh sağlığı üzerinde daha etkili olduğunu göstermektedir. Araştırma bulgularına göre psikolojik dayanıklılık puanları cinsiyete göre anlamlı derece farklılaşmamaktadır. $\mathrm{Bu}$ araştırma sonucuna paralel olarak Sezgin (2012), Karataş (2016) ve Bektaş da (2018) cinsiyetin psikolojik dayanıklılık üzerinde etkili olmadığını saptamıştır. Buna karşın Eryılmaz (2012); Önder ve Gülay (2008); Güngörmüş, Okanl1, Kocabeyoğlu (2015); Bozgeyikli ve Şat, (2014) cinsiyetin psikolojik dayanıklılık puanlarını anlamlı farklılaştırdığını saptamıştır.

$\mathrm{Bu}$ araştırmada eğitim düzeyinin psikolojik dayanıklılık puanlarını anlamlı farklılaştırmadığı saptanmıştır. Araştırma verilerine paralel olarak Boell, Silva, Hegadoren, (2016); Karabulut ve Balcı (2017); Küçüktatlıdil (2016) eğitim düzeyinin psikolojik dayanıklılık puanlarını anlamlı farklılaştırmadığını bulmuştur; fakat Bonanno, Galea, Bucciarelli ve Vlahov, (2007); Bozgeyikli ve Şat, (2014); Soyer, Gülle, Mızrak, Zengin ve Kaya (2013) araştırmalarında eğitim düzeyinin psikolojik dayanıklılık puanlarını anlamlı farklılaştırdığını belirten sonuçlar bulmuştur.

$\mathrm{Bu}$ araştırmada ekonomik durum algısının psikolojik dayanıklılık puanlarını anlamlı farklılaştırmadığı saptanmıştır. Bu bulguya zıt olarak Güngörmüş vd. (2015) ekonomik durumun psikolojik dayanıklılık puanlarını anlamlı farklılaştırdığını saptamıştır. $\mathrm{Bu}$ araştırmanın verileri ekonomik durumun anlamlı etkisinin olmadığı bulgusuna sahip olsa da psikolojik dayanıklılık puan ortalamaları yüksek ekonomik duruma sahip olmayla paralel olarak artmaktadır. Campbell-Sills, Forde ve Stein (2009) çalışmalarında gelir düzeyi düşük bireylerin psikolojik dayanıklılık düzeylerinin de düşük olduğu sonucuna ulaşılmıştır. Alan yazında ekonomik düzeyin düşük olmasının ruh sağlığını olumsuz etkileyen risk faktörlerinden olduğu ifade edilmektedir (Vanderbilt-Adriance, 2006). Bu durum Maslow'un ihtiyaçlar hiyerarşisindeki temel ihtiyaçları gidermek için ekonomik gücün gerektiği düşüncesini doğrulamaktadır.

$\mathrm{Bu}$ araştırmada medeni durum psikolojik dayanıklılık puanlarını anlamlı farklılaştırmaktadır. Araştırma verilerine paralel olarak Bozgeyikli ve Şat, (2014) medeni durumun psikolojik dayanıklılık puanlarını anlamlı derecede farklılaştırdığ s sonucuna ulaşmıştır. Buna karşın Kırımoğlu, Çokluk ve Yıldırım (2012); Gökmen (2014); Sönmezer (2015), medeni duruma göre anlamlı bir fark olmadığını belirtmişlerdir.

Yapılan analizlerde iyimserlik, özgecilik ve medeni durumun psikolojik dayanıklılığın güçlü yordayıcıları olduğu tespit edilmiştir. Günümüzde iyimserlik ve özgecilik pozitif psikolojide önemli bir araştırma alanına dönüşmüştür. İyimserlik ve özgeciliğin psikolojik dayanıklılığı güçlendiren özellikler olduğu düşünüldügünden mevcut araştırmacılar da bu olumlu kişilik özelliklerini araştırmışlardır (Seligman ve Mather, 2002). Psikolojik dayanıklılığın gelişiminde, yaşanan risklerin belirlenmesi, meydana getirdiği olumsuzlukların azaltılması ya da mümkünse bu etkilerin yok edilmesi için koruyucu unsurların varlığı çok önemlidir (Çam ve Büyükbayram, 2017). İyimserlik ve özgecilik de psikolojik dayanıklılığı etkileyen kişisel koruyucu faktörler olarak karşımıza çıkmaktadır (Cheak, 2013; McAllister, 2013; Potter vd., 2013; Çam, Öztürk-Turgut ve Büyükbayram (2014).

Pozitif bakış açısıyla yapılan çalışmalarda da psikolojik dayanıklılığa ilişkin niteliklerden birinin de iyimserlik (Peterson, 2000) olduğu bilinmektedir. Ruthig, Haynes, 
Stupnisky ve Perry, (2009) iyimserlik ve psikolojik sağlık arasındaki ilişkiyi incelediği araştırmasında iyimserliğin depresyon ve stresi yordadığını saptamıştır. Bu yönleri ile iyimserlik, olumsuz yaşantılar ve algılanan stres arasında bir kalkan gibi işlevde bulunarak ruh sağlığını korumaktadır (Segerstrom, Taylor, Kemeny, Fahey, 1998). Buradan anlaş1lıyor ki iyimser bakış açısıyla depresyon ve stresle baş ederek iyilik halini yakalamak bireyi dayanıklı hale getirmektedir. Çünkü Ergün-Başak ve Can (2018); Ergün, (2012); Eryılmaz (2012); (Karaırmak, 2007) iyimserlik arttıkça psikolojik dayanıklılığın da arttığını ifade etmektedir. İyimserlik, bireyleri kırılganlıktan uzaklaştıran, travmadan koruyan ve bireylerin moralini yükselten bir faktör olarak ele alınmakta ve psikolojik dayanıklılığı arttırmada önemli bir rolü olduğu vurgulanmaktadır (Gillham ve Reivich, 2004). Araştırmaların büyük bir çoğunluğu psikolojik dayanıklılıkla iyimserlik (Luthar, 1999; Goel, Akarte, Agrawal, Yadav, 2016); Özdemir, (2017) arasındaki ilişkileri gözler önüne sermektedir. Bu araştırmalar psikolojik dayanıklılığı yordayan en önemli faktörün iyimserlik olduğunu ortaya koymaktadır (Terzi, 2008). İyimserlik belli bir alanla ilgili özel bir tutum değil genel bir eğilim olarak görülmektedir (Scheier ve Carver, 1992). Bu yönüyle iyimserlik ruh sağlığını koruyucu bir faktör olarak karşımıza çıkmaktadır (Baum, 2008; Masten, 2014) ve ayrıca iyimserliğin bazı aracı faktörlerle fiziksel sağlık ve ruh sağlığını etkilediği bilinmektedir (Vaillant, 2012). İyimserlik bu bulgular ışığında ve bir kişilik eğilimi olarak ruh sağlığını olumlu etkileyen bir özelliktir. İyimserlik koşullara bağlı olarak ortaya çıkan zorlanmaların insan psikolojisi üzerindeki olumsuz etkilerini azaltarak ruh sağlığını olumlu yönde etkilemektedir (Segerstrom vd., 1998).

Özgeci davranış da bireyin kendini gerçekleştirmesi için psikolojik sağlı̆̆ın aracısıdır (Maslow, 2001). Ayrıca olumsuz koşullarla sağlıklı bir biçimde başa çıkabilmede önemli bir faktör olan özgecilik psikolojik dayanıklılığı artıran bir özelliktir (Beltman, Mansfield ve Price, 2011). Yaşam doyumu ve özgeci davranış arasında pozitif yönde bir ilişki vardır ve özgecilik yaşam doyumunun yordayıcısıdır. (Ümmet, 2012). Dolayısıyla mevcut yaşantısından doyum sağlayan birey özgeci davranma eğilimi sergilerken aynı zamanda ruh sağlığına olumlu katkıda bulunarak daha dayanıklı hale dönüşmektedir. Schwartz vd., (2009) özgeciliğin sağlık ve psikolojik iyi olmayla olumlu ilişkisinin olduğunu saptamışlardır. Bu özelliklere sahip bireylerin medeni durumu da ruh sağlığını etkilemektedir. Sosyal destek ve baş etme mekanizmalarını kuvvetlendiren bir unsur olan ve bireyi yalnızlaşmaktan uzaklaştıran evli olmak da psikolojik dayanıklılığa olumlu katkıda bulunmaktadır.

$\mathrm{Bu}$ alan yazın verilerine baktığımızda araştırma verilerinin tutarlı sonuçlar ortaya çıkardığı görülmektedir. Araştırmamızda da iyimserlik, özgecilik ve medeni durumun psikolojik dayanıklılığ1 artırdığg saptanmıştır. Bu sonuçtan yol çıkarak koruyucu ve önleyici ruh sağlığ1 hizmeti veren bireylerin yapacakları teorik ve uygulamalı eğitimlere iyimserlik, özgecilik kavramlarını tanıtıcı ve kazandırıcı etkinlikler eklemlerinin faydalı sonuçlar vereceği düşünülmektedir. Ayrıca bireyi ruh sağlığı anlamında güçlendiren ve yalnızlıktan uzaklaşmak için birinci derece öneme sahip sosyal destek mekanizmalarının önemi konusunda bireyleri bilinçlendirmek için faaliyetler yürütülebilir. 


\section{Kaynakça}

Abraham, W. T. (2007). Dispositional optimism and pessimism: stability, change, and adaptative recovery following life event experience. Doktora Tezi. Iowa State University, Iowa.

Agaibi, C. E. \& Wilson, J. P. (2005). Trauma, PTSD and resilience a review of the literature. Trauma, Violence and Abuse, 6(3), 195-216.

Arnett, J. J. (2007). Emerging adulthood: What is it, and what is it good for? Child Development Perspectives, 1(2), 68-73.

Atarbay, S. (2017). Farklı bölümlerde ögrrenim gören üniversite ögrencilerinin sosyal kaygı düzeylerinin psikolojik dayanıklılıklarına etkisi. Yüksek Lisans Tezi, İstanbul Üniversitesi, Eğitim Bilimleri Enstitüsü, İstanbul.

Aydın, E. (2018). Çocukluk çă̆g travmatik yaşantılarının psikolojik sağlamlık ve depresyon belirtileri üzerine etkisi. Yüksek Lisans Tezi, Fatih Sultan Mehmet Vakıf Üniversitesi, Sosyal Bilimler Enstitüsü, İstanbul.

Babbie, E. (2012). The practice of social research (13th ed.). Canada: Wadsworth Publishing Company

Baird, B. M., Lucas, R. E., \& Donnellan, M. B. (2010). Life satisfaction across the lifespan: Findings from two nationally representative panel studies. Social Indicators Research, 99(2), 183-203.

Balcı, S. ve Yılmaz, M. (2002). İyimserlik ölçeğinin geçerlilik ve güvenilirlik çalışması. On Dokuz Mayıs Üniversitesi Ĕ̈itim Bilimleri Fakültesi Dergisi, 14, 54-60.

Basım, H. N., ve Cetin, F. (2011). The reliability and validity of the resilience scale for adults-Turkish version. Türk Psikiyatri Dergisi, 22(2), 104.

Batson C. D. (2003). Altruism and prosocial behavior, "İn Weiner IB (ed): Handbook of social psychology, 5. edition” pp. 463-485, Newyork:John Wiley \& Sons, Inc.

Baum, N. L. (2008). Building resilience: A school-based intervention for children exposed to ongoing trauma and stress. Journal of Aggression, Maltreatment \& Trauma, 10(1-2), 487-498

Bektaş, M. (2018). Evli bireylerin psikolojik sağlamlık düzeylerinin yordanması. Doktora Tezi, Dokuz Eylül Üniversitesi, Eğitim Bilimleri Enstitüsü, İzmir.

Beltman, S., Mansfield, C. \& Price, C. (2011) Thriving not just surviving: A review of research on teacher resilience. Educational Research Review, 6, 185-207.

Benson, H.P. (2007). Children's dispositional optimism and pessimism: social and emotional outcomes. Doktora Tezi, Seattle Pacific University, Seattle.

Boehm, J. K., Chen Y., Williams, D. R., Ryff, C., \& Kubzansky, L. D. (2015) Unequally distributed psychological assets: are there social disparities in optimism, life satisfaction, and positive affect. PLoS One. ;10(2): e0118066. https://doi.org/10.1371/journal.pone.0118066.

Boell, J. E. W., Silva, D. M. G. V. \& Hegadoren, K. M. (2016). Sociodemographic factors and health conditions associated with the resilience of people with chronic diseases: A cross sectional study. Revista Latino-Americana Enfermagem. 24, e2786 doi: 10.1590/1518-83451205.2786.

Bonanno, G. A. (2004). Loss, trauma, and human resilience: Have we underestimated the human capacity to thrive after extremely aversive events? American Psychologist, 59(1) , 20-28.

Bonanno, G., Galea, S., Bucciarelli, A. \& Vlahov, D. (2007). What predicts psychological resilience after disaster? the role of demographics, resources, and life stress. Journal of Consulting and Clinical Psychology. 75(5), 671-82. doi:10.1037/0022-006X.75.5.671.

Bozgeyikli, H., ve Şat, A. (2014). Öğretmenlerde psikolojik dayanıklılık ve örgütsel vatandaşlık davranışlarının bazı değişkenler açısından incelenmesi: Özel okul örneği. Hak İş Uluslararası Emek ve Toplum Dergisi, 3(5), 172-191.

Budak, S. (2009). Psikoloji Sözlüğü. Ankara: Bilim ve Sanat Yayınları.

Büyüköztürk, Ş., Çokluk, Ö. ve Köklü, N. (2010). Sosyal bilimler için istatistik (6. baskı). Ankara: Pegem Akademik Yayınevi.

Campbell-Sills, L., Forde D. R. ve Stein, M. B. (2009). Demographic and childhood environmental predictors of resilience in a community sample. Journal of Psychiatric Research. 43(12), 10071012. 
Carver, C. S., \& Scheier, M. F. (2014). Dispositional optimism. Trends in Cognitive Sciences, 18, 293299. doi:10.1016/j.tics.2014.02.003

Castro-Schilo, L., Ferrer, E., Taylor, Z. E., Robins, R. W., Conger, R. D., \& Widaman, K. F. (2013). Parents' optimism, positive parenting, and child peer competence in Mexicanorigin families. Parenting: Science and Practice, 12, 95-112.

Chesak S. (2013). Integration and impact of stress management and resiliency training (smart) in a nurse residency program: A Feasibility Study. Theses and Dissertations, paper:347.

Chopik, W. J., Kim, E. S., \& Smith, J. (2015). Changes in optimism are associated with changes in health over time among older adults. Social Psychological and Personality Science, 6, 814-822. doi: http://dx.doi.org/10.1177/1948550615590199

Çam M. O, Öztürk-T.urgut E, ve Büyükbayram A. (2014), "Ruh sağlığı ve hastalıkları hemşireliğinde dayanıklılık ve yaratıcılık", Psikiyatri Hemşireliği Dergisi, 5(3), 160-163.

Çam, O, ve Büyükbayram A. (2015). The results of nurses' increasing emotional intelligence and resilience. Psikiyatri Hemşireliği Dergisi, 6(3), 130-136. doi: 10.5505/phd.2015.96729

Çam, O., ve Büyükbayram, A. (2017). Hemşirelerde psikolojik dayanıklılık ve etkileyen faktörler. Psikiyatri Hemşireliği Dergisi, 8(2), 118-126.

Doğan, T. ve Sapmaz, F. (2015). Özgeciliğin değerlendirilmesi ve öznel iyi oluşla ilişkisinin incelenmesi. Yayınlanmamış Çalışma. Rehberlik ve Psikolojik Danışmanlık Anabilim Dalı, Sakarya Üniversitesi.

Eisenberg, N. Fabes R. A., \& Spinrad T. L. (2006). Prosocial development, “ İn Damon W., Lerner R. M. (eds): Handbook of Child Psychology, 6. edition” pp. 646-719, Newyork:John Wiley \& Sons,

Ergün, B., (2012). Düşük gelirli ailelerden gelen üniversite öğrencilerinin öz duyarlılık, sosyal bă̆lllık ve iyimserlik ile psikolojik dayanıklılık düzeyleri arasındaki ilişkiler. Doktora Tezi. Anadolu Üniversitesi Eğitim Bilimleri Enstitüsü, Eskişehir.

Ergün-Başak, B., ve Can, G. (2018). The relationships between self-compassion, social-connectedness, optimism and psychological resilience among low-1ncome university Students. Illkögretim Online, 17(2), 768-785.

Eryılmaz, A., ve Ercan, L. (2011). Öznel iyi oluşun cinsiyet, yaş grupları ve kişilik özellikleri açısından incelenmesi. Türk Psikolojik Danışma ve Rehberlik Dergisi, 4 (36), 139-151.

Eryılmaz, S. (2012). Üniversite ögrencilerinde psikolojik să̆lamlı̆̆ yordamada yaşam doyumu, benlik saygısı, iyimserlik ve kontrol odağının incelenmesi. Yüksek Lisans Tezi. Muğla Sıtkı Koçman Üniversitesi, Eğitim Bilimleri Enstitüsü. Muğla.

Folkman, S. \& Lazarus, R. S. (1990). Coping and emotion. İn N. L. Stein, B. Leventhal ve T. Trabasso (Ed.), Psychological and biological approaches to emotion. NJ: Lawrence Erlbaum Associates.

Foureur M, Besley K, Burton G, Yu N, \& Crisp, J. (2013). Enhancing the resilience of nurses and midwives: pilot of a mindfulness-based program for increased health, sense of coherence and decreased depression, anxiety and stress. Contemp Nurse, 45(1), 114-125

Gillham J. \& Reivich, K. (2004). Cultivating optimism in childhood and adolescence. Annals of the American Academy of Political and Social Science, 591, 146-163.

Goel, A. D., Akarte, S. V., Agrawal, S. P., \& Yadav, V. (2016). Longitudinal assessment of depression, stress, and burnout in medical students. Journal of neurosciences in rural practice, 7(4), 493-498.

Gökmen, B. (2014). Özel eğitim okulu yöneticilerinin psikolojik dayanıklılık ve iş doyumları arasındaki ilişkinin incelenmesi (İstanbul Örneği), Yüksek Lisans Tezi, İstanbul Aydın Üniversitesi, Sosyal Bilimler Enstitüsü, İstanbul.

Güngörmüş, K., Okanlı, A., ve Kocabeyoğlu, T. (2015). Hemşirelik öğrencilerinin psikolojik dayanıklılıkları ve etkileyen faktörler. Psikiyatri Hemşireliği Dergisi, 6(1), 9-14.

Herrman, H., Stewart, D. E., Diaz-Granados, N., Berger, E. L., Jackson, B. ve Yuen, T. (2011). What is resilience?. Canadian Journal of Psychiatry. Revue Canadienne De Psychiatrie, 56(5), 258-265.

Huck, S. W. (2008). Reading statistics and research, 5th Edition. New York: Pearson

Jacelon C. S. (1997) The trait and process of resilience. Journal of Advanced Nursing, , 25, 123-129 
Karabulut, N. ve Balcı, A. (2017). Okul yöneticilerinin yılmazlık düzeyi ve denetim odağı ile ilişkisi. Trakya Üniversitesi Eğitim Fakültesi Dergisi. 7(1), 196-214

Karacaoğlu, K., ve Köktaş, G. (2016). Psikolojik dayanıklılık ve psikolojik iyi olma ilişkisinde iyimserliğin aracı rolü: Hastane çalışanları üzerine bir araştırma. İş ve İnsan Dergisi, 3(2), 119127.

Kararrmak, Ö. (2007). Investigation of personal qualities contributing to psyhological resilience among earthquake survivors: A model testing study. Doktora Tezi, Orta Doğu Teknik Üniversitesi, Sosyal Bilimler Enstitüsü, Ankara.

Karataş, R. (2016). Özel Eğitim okullarında çalışan ögrretmenlerin psikolojik dayanıklılık düzeyleri ve başa çıma stratejilerinin incelenmesi. Yüksek Lisans Tezi. Hacettepe Üniversitesi, Eğitim Bilimleri Enstitüsü, Ankara.

Kesken J. ve Ayyıldız N. A. (2008). "Liderlik yaklaşımlarında yeni perspektifler: Pozitif ve otantik liderlik", Ege Akademik Bakıs, 8(2): 729-754.

Kırımoğlu, H., Çokluk, G. F. ve Yıldırım, Y. (2012). Türk antrenörlerin yılmazlık düzeylerinin incelenmesi. Elektronik Sosyal Bilimler Dergisi, 11(39), 115- 127.

Kobau, R., Seligman, M. E. P., Peterson, C., Diener, E. D., Zack, M. M., Chapman, D., et al., (2011). Mental health promotion in public health: Perspectives and strategies from positive psychology. American Journal of Public Health, 101(8), 1-9. doi: 10.2105/AJPH.2010.300083

Kumpfer, K. L. (1999). Factors and processes contributing to resilience: The resilience framework. In M. D. Glantz, \& J. L. Johnson, (Eds), Resilience and development: Positive life adaptations pp. 179224. New York: Kluwer Academic/Plenum Publishers.

Küçüktatlıdil, S. (2016). Sigorta sektöründe çalışan kişilerin psikolojik dayanıklllık ve stresle başetme stratejilerinin bazı değişkenler açısından incelenmesi. Yüksek Lisans Tezi, Nişantaşı Üniversitesi Sosyal Bilimler Enstitüsü, İstanbul.

Lee L, Piliavin J. A., \& Call R. A. V. (1999) "Giving time, mone, and blood: similarities and differences. Social Psychology Quarterly. 62(3), 276-290

Luthar, S. S. (1999). Measurement issues in the empirical study of resilience: An overview. In M. Glanz, \& J. L. Johnson (Eds.), Resilience and development: Positive life adaptations pp. 129-160. New York: Plenum.

Maddi, S. R. (1998). Dispositional hardiness in health and effectiveness. İn H. S. Friedman (Ed.). Encyclopedia of Mental Health. San Diego, CA: Academic Press.

Magno, C., Parinas, N. \& Mamauag, M. (2008). The influence of self-mastery and communal-mastery on building a model of resiliency. Philippine Journal of Counseling Psychology, 10(1), 1-23.

Maslow, A. (2001). İnsan olmanın psikolojisi. (Çev. O. Gündüz), İstanbul: Kuraldışı Yayınları.

Masten, A. S. (2014). Ordinary magic-resilience in development. New York: The Guilford Press.

McAllister M. (2013). Resilience: a personal attribute, social process and key professional resource for the enhancement of the nursing role. Prof Inferm, 66, 55-62.

Mellor, D., Hayashi, Y., Stokes, M., Firth, L., Lake, L., Staples, et al. (2008). Volunteering and its relationship with personal and neighbourhood wellbeing. Nonprofit and Voluntary Sector Quarterly, 38(1), 144- 159.

Mens, M. G., Scheier, C. S., \& Carver, C. S. (2016). Optimism. In C. R. Snyder, S. J. Lopez, L. M. Edwards, \& S. C. Marques (Eds.), Handbook of positive psychology (3rd ed.). New York, NY: Oxford University Press. Advanced online publication.

Orth, U., \& Robins, R. W. (2014). The development of self-esteem. Current Directions in Psychological Science, 23, 381-387.

Önder A, Gülay H. (2008). İlköğretim 8.sınıf öğrencilerinin psikolojik sağlamlığının çeşitli değiş̧kenler açısından incelenmesi. Dokuz Eylül Üniversitesi Buca Eğitim Fakültesi Dergisi;23, 192-197.

Özdemir, E. (2017). Sporcuların ve sedanterlerin psikolojik sağlamlık, benlik saygısl, iyimserlik ve kontrol odă̆g düzeylerinin karşılaştırılması. Yüksek Lisans Tezi, Muğla Sitkı Koçman Üniversitesi, Sağlık Bilimleri Enstitüsü, Muğla. 
Parmaksız İ., ve Avşaroğlu S. (2012). Öğretmen adaylarının benlik saygısı düzeylerine göre iyimserlik ve stresle başaçıkma stillerinin incelenmesi. İlköğretim Online, 11(2), 543-555.

Peterson, C. (2000). The future of optimism. American Psychologist, 55(1), 44-45

Potter P., Deshields T., Berger J. A., Clarke M., Olsen S., \& Chen L. (2013), "Evaluation of a compassion fatigue resiliency program for oncology nurses", Oncol Nurs Forum, 40(2), 180-187.

Ruthig, J.C., Haynes, T.L., Stupnisky, R. H., \& Perry, R. P. (2009). Perceived academic control: Mediating the effects of optimism and social support on college students' psychological health. Social psychology of education, 12(2), 233-249. DOI 10.1007/s11218-008-9079-6

Scheier, M. F. \& Carver, C. S. (1992). Effects of optimism on psychological and physical well-being: Theoretical overview and empirical update. Cognitive Therapy and Research, 16(2), 201-228.

Schwartz, C. E., Keyl, P. M., Marcum, J. P., \& Bode, R. (2009). Helping others shows differential benefits on health and well-being for male and female teens. Journal Happiness Studies, 10(4), 431-448. 8 doi:10.1007/s10902-008-9098-1

Segerstrom, C., Taylor, S. E., Kemeny, M. E. \& Fahey, J. L. (1998). Optimism associated with mood, coping, and immune change in response to stress. Journal of Personality and Social Psychology, 74(6), 1646-1655.

Seligman, M. (1999). Teaching positive psychology. APA Monitor on Psychology, 30(7). Erişim adresi: http://www.apa.org.

Seligman, M. E. P. (2007). Gerçek mutluluk. (Çev: S. Kunt Akbaş), Ankara: HYB Basım Yayın.

Seligman, M., \& Mather, P. (2002). Authentic happiness: using the nev positive psychology to realize your potantial for lasting fulfilment. New York: Free Pre

Seligman, M.E.P. (1998). Positive Social Science. APA Monitor. 29(4), 2,5.

Sezer, Ö., ve Genç, H. (2018). The relation between altruism and positive perception and social comparison in preservice teachers. The Journal of International Social Research, 11(58), 489-495

Sezgin, F. (2012). İlköğretim okulu öğretmenlerinin psikolojik dayanıklılık düzeylerinin incelenmesi. Kastamonu Eğitim Dergisi. 20(2), 489-502.

Soyer, F., Gülle, M., Mizrak, O., Zengin, S. ve Kaya, E. (2013). Spor yapan bedensel engelli bireylerin çeşitli değişkenlere göre yllmaz düzeylerinin incelenmesi. Niğde Üniversitesi Beden Eğitimi ve Spor Bilimleri Dergisi, 7(2), 126-136.

Sönmezer B. (2015). Öğretmenlerin tükenmişlik ve psikolojik dayanıklllı düzeylerinin incelenmesi. Yüksek Lisans Tezi, Erciyes Üniversitesi, Eğitim Bilimleri Enstitüsü, Kayseri.

Şahin, Y. (2015). Üniversite ögrencilerinin mutluluk, iyimserlik ve özgecilik düzeylerinin incelenmesi. Yüksek Lisan Tezi, Gaziosmanpaşa Üniversitesi, Eğitim Bilimleri Enstitüsü, Tokat.

Taylor, S. E., Peplau, L. A., \& Sears, D. O. (2010). Sosyal psikoloji. (Çev. A. Dönmez), İstanbul: İmge Kitabevi Yayınları.

Taylor, Z. E., Widaman, K. F., Robins, R. W., Jochem, R., Early, D. R., \& Conger, R. D. (2012). Dispositional optimism: A psychological resource for Mexican-origin mothers experiencing economic stress. Journal of Family Psychology, 26(1), 133-139. doi: http://dx.doi.org/10.1037/a0026755

Terzi, Ş. (2008). Üniversite öğrencilerinde kendini toparlama gücünün içsel koruyucu faktörlerle ilişsisi. Hacettepe Üniversitesi Eğitim Fakültesi Dergisi, 35, 297-306.

Tümlü, G. Ü., ve Recepoğlu, E. (2013). Üniversite akademik personelinin psikolojik dayanıklılık ve yaşam doyumu arasındaki ilişki. Yüksek Ögretim ve Bilim , 3(2), 205-213.

Ümmet, D. (2012). Üniversite ögrencilerinde özgecilik davranışının transaksiyonel analiz ego durumları ve yaşam doyumu bağlamında incelenmesi. Doktora Tezi, Marmara Üniversitesi, Eğitim Bilimleri Enstitüsü. İstanbul.

Vaillant, G. E. (2012). Triumphs of experience: The men of the Harvard grant study. Cambridge, Mass: Belknap Press of Harvard University Press.

Vanderbilt-Adriance E. (2006). Protective factors and the development of resilience among boys from low-income families. Unpublished master's thesis, McGill University. 
Wang, J. L. \& Zhang, D. J. (2015). Resilience theory and its implications for chinese adolescents. Psychological Reports: Disability \& Trauma, 117(2), 354-375.

Weinstein, N., \& Ryan, R. M. (2010). When helping helps: Autonomous motivation for prosocial behavior and its influence on well-being for the helper and recipient. Journal of personality and social psychology, 98(2), 222-244. 


\section{Extended Abstract}

\section{Introduction}

When we think about today's society, problems have become inevitable. Therefore, mental health experts have a very important duty. Psychological resilience, optimism and altruism are important dynamics that affect mental health. The concept of psychological resilience is a personality trait that expresses a person's performance, health and well-being in stressful times. Psychological resilience is a feature that reduces the negative consequences of stress and facilitates adaptation. At the same time, psychological resilience is a feature that can be learned. For this reason, it is important to know the optimism and altruistic behavior that strengthens this feature in order to provide psychological resilience. Optimism is the positive beliefs about the future of the individual as a positive point of view which is generalized and invariably maintained in all areas of life. Research shows that optimistic people have better physical and mental health, longer lifespan, more positive social relationships, and better coping skills. This situation shows itself as a better mental health. Acting altruist is doing voluntarily without waiting for a response, except for the satisfaction that is provided by helping others. Altruistic behavior is a behavior that will be obtained by learning and modeling. By bringing this behavior to individuals, a positive effect can be made on the mental health of individuals. Altruism is a behavior that manifests itself with optimism. In this tendency, it affects individuals positively as mental health. Therefore, it is aimed to determine the predictive effect of optimism and altruistic behaviors in increasing psychological resilience, since it is thought that optimistic and altruistic behaviors of adults will increase psychological resilience. This study is thought to make an original contribution to the literature.

\section{Method}

This research is a relational study aimed at examining the relationship between optimism and altruism and psychological resilience in adult individuals. The sample consists of 389 (Female: 198, Male: 191) adult participants living in Central Anatolia. Their ages ranged from 20 to 73 years $(\mathrm{M} \pm \mathrm{SD}=30.17 \pm 10.65)$. Participants were randomly selected volunteers. In this study, Optimism Scale, Altruism Scale and Psychological Resilience Scale and personal information form developed by the researcher were used. The validity and reliability of the measurement tools used in the study were statistically determined. Hierarchical regression analysis, $t$ test and ANOVA and pearson correlation were used to analyze the data. Psychological resilience scores differed according to the marital status variable. Therefore, marital status was included as a dummy variable in regression analysis. A significant relationship was found between the variables included in the regression analysis.

\section{Results}

In the analyzes, it was found that marital status significantly differentiated psychological resilience scores. On the other hand, gender, place of living, education level and economic status did not differ significantly. The hierarchical regression analysis was performed in 3 steps. According to the results of hierarchical regression analysis, one of the predictors of psychological resilience was found to be a high predictor of psychological resilience as $27 \%$ with the marital status control variable and $30 \%$ with altruistic behavior. These findings show that altruistic behavior and optimism are very effective in predicting psychological resilience. 


\section{Discussion}

The demographic variables used in this study did not affect psychological resilience. Only marital status affected psychological resilience. When the literature is reviewed, there are studies supporting these findings as well as studies determining the opposite. Today, optimism and altruism have become an important field of research in positive psychology. Since it is thought that there are traits that strengthen psychological resilience, current researchers also deal with positive personality traits such as optimism, psychological resilience and altruism. Research shows that optimism is the most important factor predicting psychological resilience. Optimism and altruism are also personal protective factors affecting psychological resilience. They found that altruism had a positive relationship with health and psychological well-being. Optimism and altruism are predictors of psychological resilience. In the literature, there are research results that support this predictor. When we look at the literature data of this field, it is seen that the research data produce consistent results. Based on this result, it is thought that adding optimistic and altruistic activities to the theoretical and practical trainings of protective and preventive mental health service individuals will give beneficial results. Social support strengthens the individual in terms of mental health and removes it from loneliness. Activities can be carried out to raise awareness of individuals.

This research is limited to the measurement tools and research sample used. This research is original with the adult sample in which the data were collected. Because most of the research in the literature is composed of adolescents and university students. 